Dra. Noemí Morejón Llamas

Universidad Pablo de Olavide. Centro Universitario San Isidoro

@ nmorejon@centrosanisidoro.es (iD 0000-0001-6927-1931
- Recibido / Received 6 de noviembre de 2020

- Aceptado / Acepted 11 de noviembre de 2020

- Páginas / Pages De la 119 a la 138

- ISSN: $1885-365 X$

\title{
Infodemia y dependencia informativa: la función ética de la televisión pública andaluza durante la crisis del Covid-19
}

\section{Infodemic and informational dependence: the ethical function of Andalusian public television during the Covid-19 crisis}

\section{RESUMEN:}

El objetivo de esta investigación persigue analizar el papel ético y pedagógico de la televisión pública andaluza durante la pandemia, atendiendo al tratamiento de las fake news desde la teoría de la agenda setting y el framing. Para esclarecer el grado de importancia en el tratamiento informativo aplicaremos el análisis de contenido desde una perspectiva estructural compleja, ciñéndonos a una muestra de 24 noticias aparecidas en Canal Sur TV durante el estado de alarma. El estudio se enmarca en la incertidumbre y dependencia informativa como causas directas de la infodemia (Ghebreyesus, 2020; Zarocostas, 2020), así como de la desestabilidad informativa y emocional en las que emergen las noticias falsas. La originalidad del trabajo radica en la relación transdisciplinar entre infoxicación, redes sociales y responsabilidad periodística en un contexto de vulnerabilidad social a consecuencia del Covid-19. Los resultados que se desprenden del análisis sobre los indicadores variables que condicionan la producción audiovisual y las variables referidas al contenido de la noticia diagnostican una falta de concordancia entre el problema de los desórdenes informativos y el tratamiento en la televisión. Esto nos hace suponer una falta de responsabilidad desde los medios de titularidad pública, que en momentos de inestabilidad, necesitan alfabetizar mediáticamente al ciudadano.

\section{PALABRAS CLAVE:}

Infodemia; Fake news; Televisión, Ética; Agenda setting; Framing.

\section{ABSTRACT:}

The objective of this research seeks to analyze the ethical and pedagogical role of Andalusian public television during the pandemic, taking into account the treatment of fake news from the theory of agenda setting and framing. To clarify 
the degree of importance in the news treatment, we will apply content analysis from a complex structural perspective, sticking to a sample of 24 news items that appeared on Canal Sur Tv during the state of alarm. The study is framed in the uncertainty and information dependence as direct causes of the infodemic (OMS, 2020; Zaracostas, 2020), as well as the informational and emotional instability in which false news emerge. The originality of the work lies in the transdisciplinary relationship between infoxication, social networks and journalistic responsibility in a context of social vulnerability as a result of Covid-19. The results that emerge from the analysis of the variable indicators that condition audiovisual production and the variables related to the content of the news diagnose a lack of concordance between the problem of news disorders and the treatment on television. This suggests a lack of responsibility from publicly owned media, which during times of instability, needs to educate citizens through media literacy.

KEY WORDS:

Infodemic; Fake news; Television; Ethical; Agenda setting; Framing.

\section{Introducción}

La crisis del Covid-19 ha ocupado todo el espectro informativo desde que estalló la pandemia y se produjo su llegada a España. Los espacios informativos, en cualquiera de sus formatos, se han adaptado a una situación que no ha dejado lugar a otras informaciones, reconfigurando así la propia agenda setting de los medios (McCombs y Shaw, 1972) y orquestando un nuevo producto monotemático.

A esto se suma la proliferación de noticias falsas o fake news que han minado esos espacios de información y que son un apéndice de la desinformación (Serrano, 2009), si entendemos a estas englobadas dentro de los desórdenes informativos (García Marín, 2020; Ireton y Posetti, 2018).

En esta ocasión, esa introducción de noticias falsas con un interés movilizador de la opinión pública (Lippman, 1922) ha calado en una sociedad más sensible y más expuesta al mundo digital. Por ello, la crisis del Covid-19 ha supuesto el caldo de cultivo idóneo para la proliferación de la denominada infodemia (Ghebreyesus, 2020; Zarocostas, 2020), cuyo objetivo se apoya en formar rápidamente una opinión pública polarizada, según Mora (2005) «la opinión pública se manifiesta en fenómenos a corto plazo» (citado en Rubio Ferreres, 2009).

Desde la llegada de las nuevas tecnologías, la infoxicación actúa en las democracias como una censura encubierta que «funciona por demasía, por acumulación, por asfixia» (Ramonet, 1998: 40). La desinformación aglutina los condicionantes sociales, económicos y políticos de los nuevos tiempos y una modificación en las conductas asociadas que derivan en un asunto complejo y multidisciplinar (Torres Soriano, 2020: 9).

Durante la pandemia se ha generado una vasta cantidad de información, producida exponencialmente por las instituciones y organismos gestores de la crisis, que ha modificado a través de la agenda política y pública la selección de noticias (Rogers y Dearing, 1988). Canel, Llamas y Rey afirman que «los medios de difusión transfieren al público tanto la percepción de los "temas" o "problemas" sobre los cuales se ha de fijar la atención como su propia importancia relativa o "prominencia" dentro de la propia agenda" (citado en Macedo García, 2017: 92).

Los medios de comunicación tradicionales como la prensa, la radio y la televisión han pretendido cumplir su papel ético dando cuenta de las desinformaciones y fake news aparecidas en redes sociales posicionándolas en su agenda setting. La selección de noticias (Casero-Ripollés, 2008: 193) también se ha visto condicionada por lo acontecido en el mundo 
cibernético, actuando así a posteriori como si de una herramienta de fact-cheeking (Amorós García, 2018: 154) se tratase. En este sentido, los medios de comunicación públicos tienen la obligación moral de cumplir su función ética y social, pues solo de esta manera la esfera pública presentará la realidad de manera crítica (Habermas, 1992).

Además de la sensibilidad de la audiencia, que ha sufrido un aislamiento por primera vez en generaciones -en España con el Real Decreto 463/2020, de 14 de marzo-, la necesidad de información para comprender la realidad ha otorgado a la comunicación y a los medios un papel preponderante, intensificado en situaciones de crisis como la presente (Lippman, 1922).

\section{Estado de la cuestión}

\subsection{INCERTIDUMBRE, DEPENDENCIA INFORMATIVA Y AUDIENCIAS}

Partiendo de la Teoría de la Dependencia (Ball-Rokeach y DeFleur, 1976) y dada la tiranía de la velocidad (Roche Cárcel, 2009) a la que el ser humano está sujeto en situaciones de cotidianidad por la aceleración de los ritmos presenciales y virtuales, «hemos pasado de una identidad a priori y sustancial a otra a posteriori y situacional que nos ha convertido en seres humanos llenos de posibilidades aunque también de incertidumbres».

El miedo a lo desconocido se ha incrementado con la pandemia y el confinamiento, que ha virado en una pérdida de control del individuo sobre su entorno, distorsionando los cimientos del presente y tornándose en confusión y miedo ante dicha incertidumbre. Por primera vez en el nuevo siglo nos enfrentamos a la angustia, a la falta de certezas y a la ausencia de conocimiento seguro al carecer de una perspectiva histórica y entender que la medicina es un método evolutivo y no absoluto que ejerce sus aportaciones científicas a través del dinamismo (Rey, Ladero y Muñoz, 2020).

Para comprender nuestro entorno, la audiencia ha acudido a los medios de comunicación y ha dependido de ellos con el objetivo de satisfacer su necesidad de información y supervivencia sobre algo intangible - el virus -, que ha dinamitado el control social imperante, estabilizado en España tras los movimientos sociales del $15 \mathrm{M}$ y del 150, que polarizaron la sociedad allá por 2011 (Morejón Llamas, 2014).

Como apunta Ball-Rokeach (1985) los individuos aumentan su dependencia informativa cuando la situación es incomprensible o ambigua, pues es ante la falta de conocimiento necesario para dotar de significado a una situación de riesgo cuando «el sistema de medios se transforma en una fuente de información vertebral dado que, en el marco de las sociedades contemporáneas, dispone de los recursos suficientes para crear significado frente a la realidad» (Baquerin de Riccitelli y Scaricabarozzi, 2010: 8).

Casero-Ripollés (2020) ha analizado el papel de los medios de comunicación estadounidenses a través de los datos secundarios de las encuestas online del Pew Research Center's American Trends Panel en Estados Unidos, comparando la situación antes y después del brote con objeto de esclarecer el impacto del Covid-19 sobre el sistema mediático. Entre sus hallazgos destacan «el resurgimiento del protagonismo de los medios tradicionales, especialmente de la televisión, y la reconexión a las noticias de los ciudadanos más alejados de la información» (Casero-Ripollés, 2020: 1). Esto deriva en una reducción de las desigualdades 
de accesibilidad a la información y por ende, en un beneficio sobre el sistema democrático. Como enfatizan Moreno, Fuentes Lara y Navarro: «In Spain, Masip et al. (2020) found that online newspapers (38.9\%) and television (33.9\%) were the main sources of information, far ahead from social media and messaging services (11.4\%), and radio (8.3\%)» (Moreno, Fuentes Lara y Navarro, 2020: 4).

El informe especial de Barlovento Comunicación (2020), que estudia el cambio de hábitos frente al televisor por la crisis del coronavirus, ejemplifica el comportamiento de la audiencia durante el estado de alarma:

- En España se consiguió el récord histórico de consumo televisivo en el mes de marzo con un total de 284 minutos por persona/día. En concreto, el domingo 15 de marzo se registró la que es hasta la fecha la jornada con mayor consumo de televisión de la historia con un total de 344 minutos por persona (5 horas y 44 minutos). Esto ha supuesto que el consumo se haya incrementado en casi el $40 \%$, un total de +88 minutos más por persona que en las primeras semanas de marzo, antes de que se decretase el estado de alarma.

- Todas las comunidades autónomas, sin excepción, incrementaron su consumo televisivo por encima del $30 \%$, siendo la franja matinal con el $65 \%$ de incremento, en la que más creció el consumo. El horario vespertino también refleja un crecimiento de casi el $50 \%$, mientras que la sobremesa lo hace en un $42 \%$.

- La información que la televisión tradicional genera repercute de manera directa en el aumento de la audiencia social al suponer más de 10 millones de tuits, casi 1 millón y medio más que el año pasado, los generados durante este periodo.

En el caso andaluz, tal como explicó el director general de la RTVA, Juande Mellado, en Comisión Parlamentaria, la audiencia de los informativos ha crecido exponencialmente, alcanzando una audiencia diaria de 2.357 .000 espectadores y convirtiéndose en «la cadena que porcentualmente ha conseguido un mayor incremento del número de espectadores al aumentar en un $28,9 \%$ (RTVA, 2020).

\subsection{INFODEMIA Y PERCEPCIÓN DE LA CRISIS SANITARIA}

La infoxicación, agravada con la crisis sanitaria, es el resultado, entre otras, de la irrupción de las nuevas tecnologías que provocan la saturación del ecosistema de noticias, en el que informarse pasa a ser una tarea cada vez más complicada. Para Casero-Ripollés (2020: 2) esto es consecuencia directa de:

- La proliferación de canales y plataformas.

- La multiplicación de los proveedores de información.

- La abundancia comunicativa.

- El aumento de la competencia entre los medios.

Lo mismo determinan López-Rico, González-Esteban y Hernández-Martínez sobre los peligros de la desinformación durante el confinamiento. La infoxicación ha complicado notablemente el acceso a «una información veraz y que nos ofrezca un análisis riguroso del 
contexto en el que vivimos» (López-Rico, González-Esteban y Hernández-Martínez, 2020: 78). Esa saturación informativa que la OMS bautizó como infodemia en febrero de 2020 está provocando en el ciudadano una desconfianza y una fragmentación en el acceso a la información de los asuntos públicos (Casero-Ripollés, 2020: 3).

El 12 de febrero un artículo publicado por el MIT Technology Review considera que «la Covid-19 es la primera pandemia global de las redes sociales (Hao y Basu, 2020), hecho que ha provocado numerosos desafíos con relación a la comunicación», (Catalán Matamoros, 2020: 1). La desinformación es una consecuencia directa de la posverdad y viceversa, entendiendo esta última según Zarzalejos (2017) «como una corriente que se vale del subjetivismo por encima de la razón o los hechos [...] y evidencia una supremacía del discurso emotivo» (citado en Estrada-Cuzcano, Alfaro-Mendives y Saavedra-Vásquez, 2020: 98).

Durante la pandemia ha tenido lugar una auténtica explosión informativa, pues «entre el 14 y el 19 de marzo, se publicaron 45.294 noticias en medios digitales, lo que supone un incremento de casi el triple de noticias más que con respecto a las 15.434 de principios de marzo» (Lázaro-Rodríguez y Herrera-Viedma, 2020: 7).

EI CAA en su Informe sobre el tratamiento informativo de la crisis del coronavirus en Canal Sur $T V$ concluye que «la crisis sanitaria del coronavirus copó el $89 \%$ de las noticias emitidas por Canal Sur TV y el 84\% de la duración de las mismas en los informativos diarios» (CAA, 2020: 106).

La propagación e incremento de fake news a través de las redes sociales ha provocado que la crisis de Covid-19 «pasa a ser también, además de una crisis de salud pública y una crisis económica, una crisis de información» (Pérez-Dasilva, Meso-Ayerdi y Mendiguren-Galdospín, 2020: 4).

Partimos de la definición que elaboran Ireton y Posetti (2018: 44) del término fake news como «desórdenes informativos», mientras tomamos de Pérez-Dasilva, Meso-Ayerdi y Mendiguren-Galdospín (2020: 4) la intencionalidad y objetivos que persiguen al definirlas como «información deliberadamente falsa, difundida por motivos económicos, ideológicos o por alguna otra razón».

Torres Soriano expone que la desinformación

extiende sus raíces en facetas tan diversas como la propia naturaleza humana y sus sesgos cognitivos, las tensiones sociales, las rivalidades geoestratégicas, la crisis de los medios de comunicación tradicionales, nuestro conocimiento imperfecto sobre los efectos de las tecnologías de la información en la sociedad, etc. (Torres Soriano, 2020: 9).

García Marín (2020: 3) señala como causas de la desinformación:

- La politización de los medios.

- La desconfianza de los ciudadanos hacia las instituciones.

- Los sesgos psicológicos y gratificaciones sociales que impulsan a los individuos a compartir fake news.

- Fracaso de las plataformas para reconocer y potenciar su papel en la solución del problema.

En palabras de Salaverría et al. (2020: 13):

Los bulos son más graves -es decir, más dolosos e incluso punibles - cuanto mayor es el nivel de falsedad y de voluntariedad en su difusión. Dicho de otro modo: 
es más grave un engaño que una descontextualización; una descontextualización es a su vez más grave que una exageración y, esta, por su parte, lo es más que una broma.

García-Marín indica que durante la pandemia «el tipo de contenido más producido es el completamente fabricado; sin embargo, los desórdenes informativos que reconfiguran algún tipo de información verídica constituyen prácticamente la mayoría de la desinformación» (2020: 10).

En el análisis de la percepción de información que han llevado a cabo Masip et al. (2020) apostillan que un 44,6\% considera que los medios de comunicación están informando de manera sensacionalista, generando alarma social, frente a un $25,5 \%$ que opina lo opuesto. Lo más notable es que el $77,36 \%$ de los encuestados se muestra de acuerdo o muy de acuerdo en el condicionamiento editorial de los medios para construir la realidad en torno al coronavirus, «esta presencia del sesgo ideológico coincide con investigaciones recientes sobre el Covid-19 (Motta et al., 2020) y puede constituir un puente hacia la desinformación» (Masip et al., 2020: 8-9).

Este sensacionalismo mueve a los telespectadores a «televisiones públicas y las versiones digitales de periódicos tradicionales», en los que sienten seguridad informativa (Masip et al., 2020: 9). Por este motivo se reporta un incremento en el consumo televisivo, pero también en los medios digitales, que ante la demanda han duplicado su producción de noticias -véase el caso de eldiario.es o 20minutos.es.

Igartua, Ortega-Mohedano y Arcila-Calderón concluyen que esa exposición a los medios de comunicación y la dependencia establecida ha contribuido negativamente a la percepción de la enfermedad:

la divulgación diaria en los medios de comunicación de cifras sobre el número de contagios y el número de víctimas, y la alarma suscitada en las primeras etapas de la pandemia ante la necesidad de «aplanar» la curva, son elementos que han contribuido notablemente al incremento de la percepción de gravedad de la enfermedad (Igartua, Ortega-Mohedano y Arcila-Calderón, 2020: 9).

\section{Objetivos e hipótesis}

Tomando como referencia la interpretación que McCombs (2006) hace del encuadre (framing) al considerarlo un macroatributo que «conforma un punto de vista dominante sobre un objeto, influyendo en la percepción pública de ese asunto y en la comprensión del mundo social en general», comprobaremos cómo actúan las televisiones públicas en la toma de consciencia y en la educación de su audiencia sobre la infoxicación y los desórdenes informativos.

El presente trabajo no se limitará a estudiar el posicionamiento en la agenda setting según su repetición y accesibilidad por parte del receptor, sino que se centrará en la aplicabilidad "en la medida en que los conceptos conectados en un mensaje tenderán igualmente a conectarse en la mente del individuo en el proceso de formación de opinión, influyendo posteriormente en las actitudes y comportamientos» (Ardèvol-Abreu, 2015: 427).

Atendiendo a este segundo nivel de la agenda setting, el estudio del framing nos permitirá interpretar cómo se presenta la información en el discurso y en el caso de hacerlo de manera incorrecta, proponer un tratamiento (McCombs, 2006) que otorgue a la televisión pública la capacidad de alfabetizar mediáticamente a la audiencia: 
Encuadrar es seleccionar algunos aspectos de una realidad que se percibe y darles más relevancia en un texto comunicativo, de manera que se promueva una definición del problema determinado, una interpretación causal, una evaluación moral y/o una recomendación de tratamiento para el asunto descrito (McCombs, 2006: 170).

Tanto en la teoría de la agenda setting como en la del framing se establecen «prioridades temáticas cuyo éxito depende de la credibilidad y el atractivo de la fuente. En cada uno de esos pasos, se perfila el encuadre» (Núñez-Gómez et al., 2020: 46).

Partiendo de esta premisa nos hacemos las siguientes preguntas de investigación:

- P.1. ¿Ha cumplido Canal Sur TV su función ética de informar y educar a la audiencia de informaciones manipuladas que tienen como fin desestabilizar la opinión pública?

- P.2. ¿Cuál ha sido el grado de importancia otorgado por la televisión pública andaluza a las fake news tomando como marco la agenda setting y el framing?

Este trabajo tiene como objetivo dilucidar si la televisión pública andaluza -Canal Sur TV - ha cumplido su función ética de informar y formar al ciudadano sobre los desórdenes informativos durante el estado de alarma. También se pretende trazar una panorámica estructural que nos permita entender cómo se está comportando la audiencia en plena crisis sanitaria en el ecosistema digital y en el sistema tradicional de medios.

Entre los objetivos secundarios destacan:

- Estudiar el consumo y la dependencia informativa durante la pandemia partiendo de la Teoría de la Dependencia y su recepción desde la acción de los medios a través de la agenda setting y el framing.

- Contextualizar el nacimiento y proliferación de fake news como consecuencia de la infoxicación y la tiranía de la velocidad a la que está sometida la audiencia y los periodistas.

\section{Metodología}

La metodología elegida para estudiar el fenómeno andaluz se fundamentará en una triangulación cuantitativa y cualitativa desde el análisis de contenido propuesto por Andréu Abela (2002) y Teso Alonso (2011), que se apoya en el marco teórico del framing, la hipótesis de la agenda setting, el newsmaking y el análisis narratológico.

Para la elección de la muestra realizamos un cribado, sobre el que consideramos necesario hacer algunas apreciaciones:

- Acotación temporal: estado de alarma (14 de marzo de 2020 a 21 de junio de 2020).

- El medio: Canal Sur Televisión.

- Informativos analizados: Buenos días Andalucía, Noticias 1 y Noticias 2, desconexiones provinciales.

- Para realizar este trabajo nos servimos de los datos cedidos por el Consejo Audiovisual de Andalucía (CAA). La catalogación del CAA supone ya un primer cribado en la obtención de la muestra.

- Una vez facilitado el número de noticias catalogadas, $n=6.782$, realizamos una búsqueda con las siguientes palabras clave: noticias falsas, fake news, bulos, desinformación, infodemia, infoxicación. 
- Tras obtener el resultado del segundo cribado $(n=24$ sobre fake news) procedemos a establecer 24 unidades de análisis.

Según la metodología propuesta por Teso Alonso (2011), elaboramos la siguiente ficha de análisis de contenido (Tabla 1), con el propósito de establecer su identidad de registro, los indicadores variables que condicionan la producción audiovisual, así como las variables referidas al contenido de la noticia.

Tabla 1. Análisis de contenido

\section{Categorías de las variables}

\section{Identidad del registro}

\section{Indicadores y variables que condicionan la producción audiovisual}

\section{Variables relativas al} contenido de la noticia

\section{Apartados de protocolo para cada categoría}

a) Fecha de emisión, programa, hora y duración

a) Indicadores de la relevancia y jerarquización empleados:

- Ubicación del registro dentro del programa informativo.

- Composición o formato de la noticia:

- Solo voz en off

- Presentador(a) solo(a)

- Presentador(a) + «colas»

- Presentador + «pieza» elaborada de antemano

- Presentador + Conexión con corresponsal o enviado especial + imágenes en «colas»

- Presentador + Conexión con corresponsal o enviado especial + «piezas»

- Presentador + entrevista en directo en plató

b) $\mathrm{N}^{\circ}$ de totales y rol

c) Procedencia y vigencia de las imágenes:

- Procedencia propia/ ajena o externa

- Reciente producción y actualidad/material de archivo

a) Contenido:

- Palabras clave de la unidad de análisis

- Frase de presentación. La frase pronunciada por el presentador del programa para presentar la noticia

- Frase resumen. Frase elaborada que resume el contenido del discurso completo de la noticia

- Tema principal, expresado mediante palabras clave

- Tema subsidiario, expresado mediante palabras clave

- Rótulo temático. Transcripción literal del texto que aparece sobreimpresionado sobre las imágenes

- Territorio. Contexto geográfico principal en el que se desarrolla en conflicto o contenido abordado en la noticia

b) El contenido en relación con un repertorio específico de palabras clave sobre el Covid-19 y las fake news:

- La frase de presentación de la noticia pronunciada por el presentador del programa.

- Los rótulos incrustados sobre las imágenes.

Fuente: elaboración propia a partir de la propuesta de Teso Alonso (2011). 


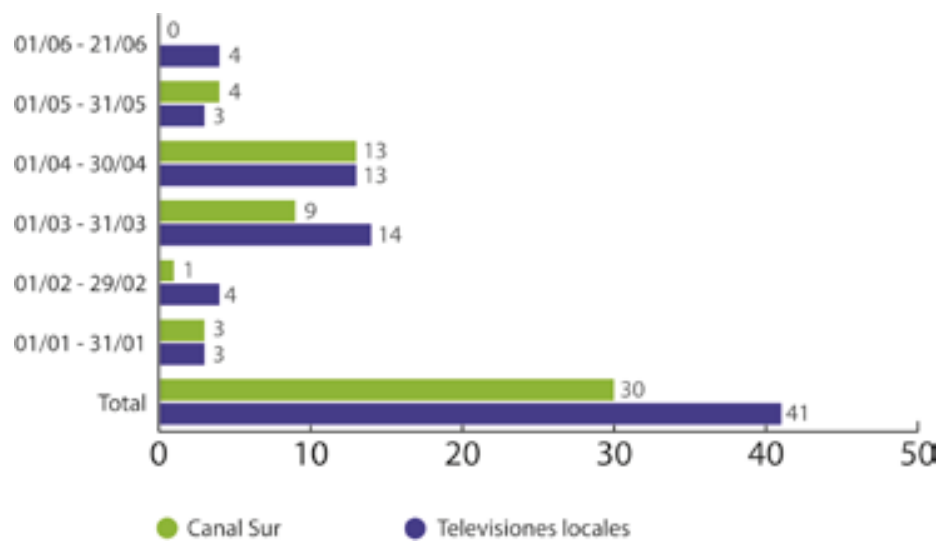

Figura 1. Fake news en las televisiones públicas de Andalucía. Fuente: elaboración propia.

\section{Resultados}

En este clima de infoxicación resulta imprescindible la responsabilidad ética de los medios de comunicación de titularidad pública, que «deben alertar a los ciudadanos sobre amenazas y peligros y proporcionar los instrumentos necesarios para realizar algunas actividades cotidianas e institucionales en la sociedad» (Sierra Caballero y Moreno Gálvez, 2011: 74).

A continuación presentamos los resultados de nuestro análisis cuantitativo y cualitativo, que abarca desde el 14 de marzo al 21 de junio de 2020 - fin del estado de alarma -, con el objetivo de comprobar si la aparición en la agenda de las fake news y de los bulos surge tras la crisis del Covid-19 o, si por el contrario, ya ocupaba un espacio en los informativos andaluces.

En la figura 1 queda de manifiesto que el incremento en el tratamiento informativo sobre fake news en la agenda de las televisiones públicas andaluzas - aquí incluimos las licencias de televisiones locales facilitadas por el CAA - coinciden en los meses de marzo $(n=9$ y $n=14)$ y abril $(n=13$ y $n=13)$. Sin embargo, en el mes de marzo existe una diferencia entre las televisiones públicas locales $(n=14)$ y la autonómica Canal Sur $(n=9)$. En los meses de enero y febrero - previo a la pandemia - la aparición de la temática sobre desórdenes informativos se mantiene estable y a la baja con respecto a los picos resultantes de la crisis del Covid-19. De ahí que en el mes de enero solamente aparezcan 3 noticias falsas en las televisiones locales y autonómicas, mientras que en febrero hallamos 4 en las locales y 1 en Canal Sur. En cuanto a junio destacan la inexistencia de fake news en la autonómica, mientras las locales recogen 4 bulos en los informativos analizados.

En la tabla 2 comparamos el número de noticias catalogadas en Canal Sur TV y en el resto de las televisiones locales públicas andaluzas. Los resultados muestran que durante el estado de alarma, de las 14.126 noticias catalogadas en las televisiones locales, solamente 32 abordaban las fake news, lo que supone un $0,23 \%$ del total de información. En cuanto a Canal Sur TV, de las 6.782 noticias catalogadas, 24 se refieren a los bulos y noticias falsas, lo que se traduce en un $0,35 \%$. 
Tabla 2. Fake news en la televisión pública andaluza

\begin{tabular}{|l|c|c|c|}
\hline \multicolumn{1}{|c|}{ Cadena } & Noticias catalogadas & Fake news & Porcentaje \\
\hline Televisiones públicas & 14.126 & 32 & $0,23 \%$ \\
\hline Canal Sur TV & 6.782 & 24 & $0,35 \%$ \\
\hline Total & 20.908 & 56 & $0,27 \%$ \\
\hline
\end{tabular}

Fuente: elaboración propia.

Si tenemos en cuenta el cómputo total de noticias catalogadas desde el 14 de marzo al 21 de junio, de 20.908 noticias solo 56 agendan la temática fake news, lo que supone una presencia del $0,27 \%$ en la agenda setting de las televisiones andaluzas.

Centrándonos en la muestra $(n=24)$ obtenida del cribado de las palabras clave fakes, bulos y desinformación en Canal Sur TV, podemos extraer que el tiempo dedicado en la agenda setting supone una cobertura de 173 minutos y 16 segundos, una cifra cercana a las 3 horas de emisión hablando sobre desórdenes informativos.

En la tabla 3 reflejamos en qué periodos se han agendado más fake news en los programas informativos analizados -Buenos Días Andalucía, Noticias 1, Noticias 2, desconexiones provinciales - y anotamos que el mes con más informaciones sobre noticias falsas y bulos fue abril con 13 unidades, seguido de los meses de marzo con 7 noticias y mayo con 4 . Es interesante señalar que el salto en los meses de marzo y abril se debe al incremento de la muestra en la catalogación, pues el CAA (2020) realizó un informe de pluralismo político en este periodo que puede ser consultado en su página web. Llama la atención la inexistencia de informaciones sobre desórdenes informativos en el mes de junio.

En cuanto a la temática, las fake news agendadas en Canal sur TV se distribuyen, tal como se representa en la figura 2 , con una diferencia sobresaliente entre los temas crónica política y sociedad, que suponen un $39 \%$ del total cada uno de ellos. La temática medios de comunicación con un $13 \%$ y sanidad con un $9 \%$ son las menos significativas en cuanto a número, pero no en cuanto a contenidos, como veremos en las conclusiones.

Tabla 3. Fake news en Canal Sur TV durante el estado de alarma

\begin{tabular}{|l|c|c|}
\hline \multicolumn{1}{|c|}{ Mes } & Noticias catalogadas & Fake news \\
\hline Mar & 2.077 & 7 \\
\hline Abr & 3.346 & 13 \\
\hline May & 677 & 4 \\
\hline Jun & 682 & 0 \\
\hline Total & 6.782 & 24 \\
\hline
\end{tabular}

Fuente: elaboración propia. 


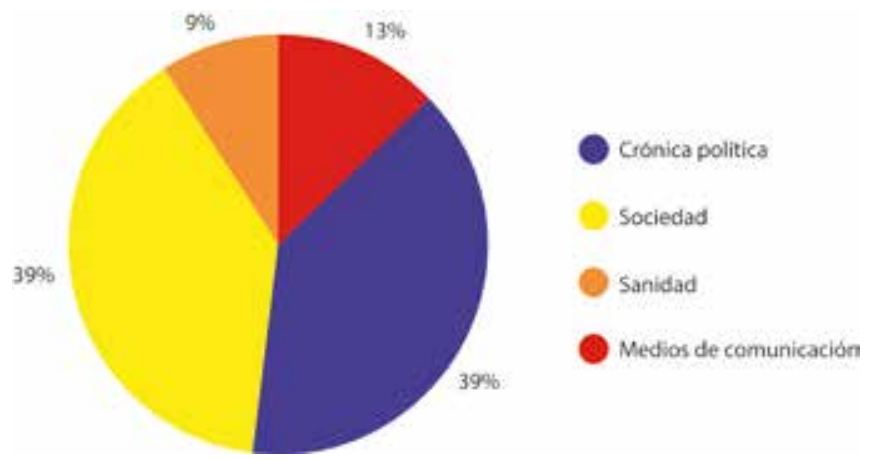

Figura 2. Temática de las fake news. Fuente: elaboración propia.

La función ética y educativa de la televisión precisa no solo de una presencia significativa en su parrilla informativa, sino también de un encuadre que centre la atención del usuario en el tema con el objetivo de facilitar las herramientas pedagógicas y comunicativas que combatan las fake news. Macedo García (2017: 97) estima que en televisión la agenda setting se puede medir en la siguiente escala:

- El lugar en el que se presenta la información.

- La sección periodística.

- El género periodístico.

- El uso de imágenes, sonidos y/o animaciones.

- El tiempo dedicado al tema.

- La presencia en resúmenes.

Tomando como marco referencial esta clasificación y apoyando nuestra investigación en la metodología de Teso Alonso (2011) analizamos la duración, ubicación, composición de la noticia y roles para entender el encuadre, pues en las situaciones de crisis, el tema se encuentra ya establecido.

La figura 3, referida a la duración de las noticias, pone de manifiesto que las noticias sobre fake news ocupan una media de 1-2 minutos, lo que arroja un $55 \%$ del total. Sin embargo, las

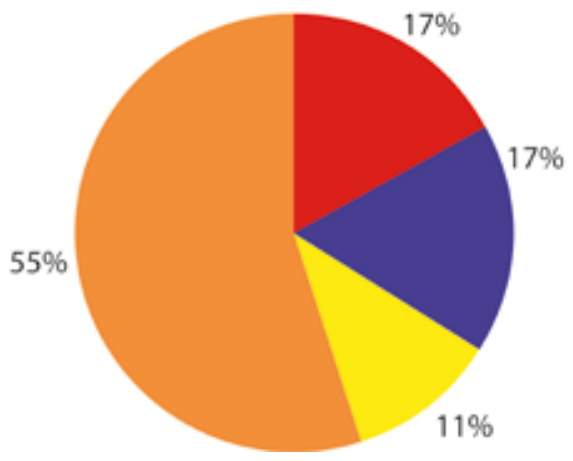

Más de 3 min.

Más de 2 min.

1 - 2 min.

Menos de $1 \mathrm{~min}$.

Figura 3. Duración de las noticias. Fuente: elaboración propia. 


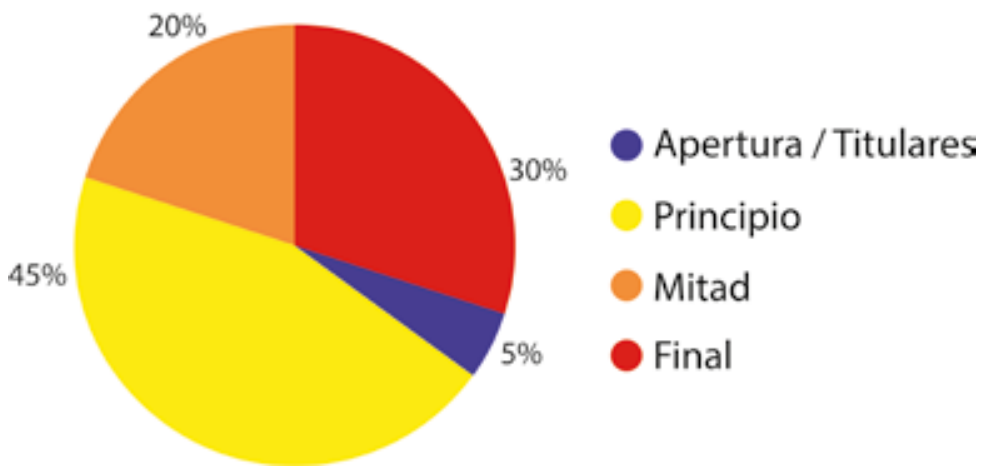

Figura 4. Ubicación de las noticias. Fuente: elaboración propia.

noticias de menos de 1 minuto y las de más de 3 coinciden en porcentaje con un 17\%, mientras que las de más de 2 se sitúan en el $11 \%$.

En cuanto a su ubicación, como observamos en la figura 4, un $45 \%$ se localiza al principio del informativo, un $30 \%$ al final y un $20 \%$ a la mitad del mismo. Resulta relevante el $5 \%$ de presencia de fake news en apertura o titulares, una cifra baja para una ubicación que enfatiza la importancia del asunto abordado por el medio (Macedo García, 2017).

La figura 5 recoge los principales roles de los totales obtenidos en la catalogación inicial, incidiendo en la figura del experto con un $35 \%$, como voz preferente en el relato. Resulta esclarecedor los datos obtenidos para los actores Gobierno (18\%) y políticos (23\%), que a pesar de haberlos diferenciado por entender el rol Gobierno-oposición, sumados suponen un $41 \%$, por encima del rol experto. Por su parte, las intervenciones de la Administración del Estado (Guardias Civiles, Fuerzas Armadas) y los representantes de asociaciones o colectivos evidencian un $12 \%$ respectivamente.

Profundizando en la presentación del discurso, el desenlace de la noticia y las palabras clave empleadas exponemos los siguientes resultados:

En la composición de la información, tal como se retrata en la figura 6, predomina con un $74 \%$ el uso de la siguiente fórmula: presentador + colas/piezas. Sin embargo, en segundo lugar encontramos la presencia de entrevistas, que si bien es deficiente con un $13 \%$, nos

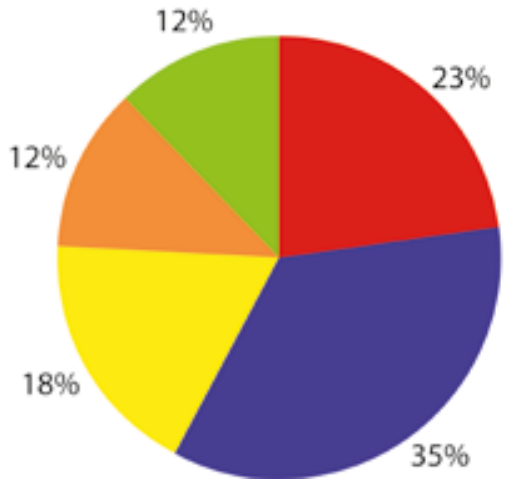

Experto

Gobierno

Administración del Estada

Politicos

Asociaciones

Figura 5. Roles de los totales. Fuente: elaboración propia. 


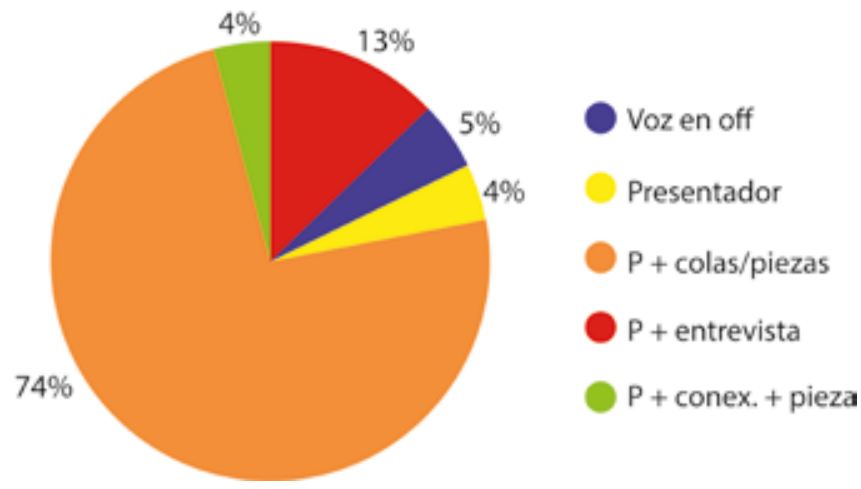

Figura 6. Composición de la información. Fuente: elaboración propia.

resulta interesante por la carga discursiva que supone. El resto de fórmulas - voz en off, presentador y presentador + conexión en directo + pieza-, suponen un $4 \%$ y un $5 \%$ en las dos últimas.

El análisis discursivo arroja datos cuantitativos que demuestran que el fenómeno fake news se presenta como un conflicto en un $52 \%$, como un riesgo en un $31 \% \mathrm{y}$, en última instancia, como un fenómeno de apariencia normalizada, $17 \%$, según se observa en la figura 7 .

Al centrarnos en el desenlace de la noticia, como ejemplificamos en la figura 8 , el encuadre de los bulos se centra principalmente en la presentación del conflicto sin presentar solución,

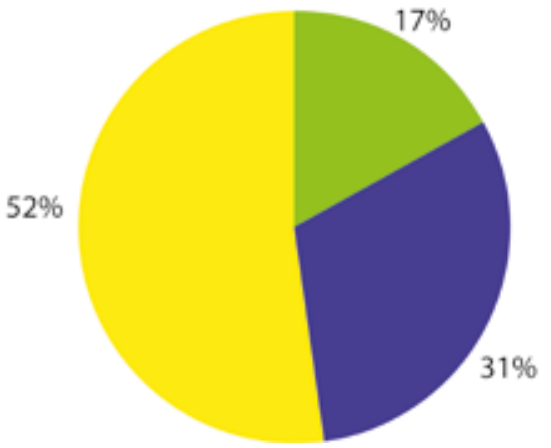

Figura 7. Presentación del discurso. Fuente: elaboración propia.

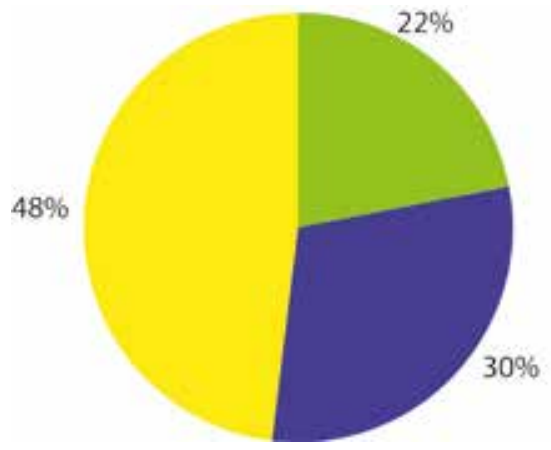

Figura 8. Desenlace de la noticia. Fuente: elaboración propia.
Riesgo

\section{Conflicto}

Apariencia de normalidad

Se plantea solución

Impasse (sin solución)

No se plantea conflicta 


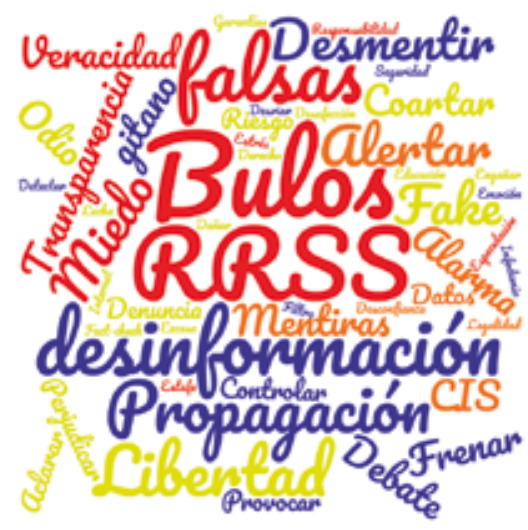

Figura 9. Nube de palabras de fake news. Fuente: elaboración propia.

$48 \%$; así como en presentar el problema y la solución, $30 \%$. No obstante, encontramos que, con un $22 \%$, el desenlace del tratamiento de las fake news no plantean ni siquiera el conflicto.

La figura 9 es el resultado de la catalogación de las palabras clave a través de una nube de palabras en la que ilustramos la terminología empleada en el discurso. Destaca el uso de algunos términos que exponemos brevemente:

- Bulo: aparece en todas las noticias y es el único término que coincide en cualquiera de los temas. Se usa como apertura a la información y se utiliza más que noticias falsas o fake news.

- Redes sociales: la hallamos hasta en 10 noticias. Se usa para contextualizar dónde nace la desinformación.

- Falsas (referidas a noticias falsas): aunque aparece de manera recurrente, en 9 ocasiones, se prefiere el uso del término bulo. El empleo de «noticias falsas» se emplea para explicar el fenómeno y no tanto para alertar de algún hecho concreto de difusión malintencionada.

- Fake: aunque el anglicismo se utiliza en menor medida, lo encontramos en 4 noticias.

- Desinformación: se recurre al término para explicar la intencionalidad del objeto de estudio.

Resaltan otras palabras que explican las consecuencias de la difusión - propagación, alarma, controlar, miedo, odio-, otras que hacen referencia a la concienciación del problema - alertar, desmentir - y otro grupo que se ciñe a la libertad/derecho de información -transparencia, libertad, derecho, veracidad.

\section{Conclusiones/Discusión}

Nuestro trabajo de investigación nos permite hacer una aproximación a la valoración sobre el tratamiento informativo de las fake news en las agendas de los medios andaluces, en concreto, del medio autonómico Canal Sur TV como expondremos a continuación:

1. Partiendo del establecimiento de la agenda setting consideramos imprescindible la repetición en el abordaje de una problemática como es la infoxicación y la eclosión y 
viralización de las fake news. Por este motivo, nos resulta insuficiente en número las noticias encontradas $(n=24)$, pues entendemos que no trasladan al telespectador la importancia real del tema.

Tampoco apreciamos un análisis estructural profundo que permita entender de dónde surgen las noticias falsas, por qué emergen y qué pretenden. Solamente respondiendo a estas preguntas básicas en las noticias emitidas consideramos que la audiencia podrá alfabetizarse mediáticamente y diferenciar la información veraz de la malintencionada. Por ende, comprendemos que el valor pedagógico y la función educadora que se le presupone a la televisión pública no se demuestra en nuestro objeto de estudio.

2. Resulta significativo que la mayoría de las noticias referentes a fake news se enmarquen dentro de la temática crónica política y sociedad ( $39 \%$ en ambas). En todas ellas la desinformación responde a un interés movilizador de la opinión pública, que pone en entredicho la labor política para con la sociedad.

3. El discurso de estas noticias se centra en describir el tipo de bulo/fake news de una manera descriptiva, aunque poco explicativa. En ningún momento se hace alusión a las repercusiones a largo plazo, aunque sí a las inmediatas, focalizando el mensaje en lo que pretende la desinformación: tambalear al partido político/gobierno al que van dirigidas. El discurso se fija, por tanto, en presentar el conflicto, aunque es limitante en la presentación de los riesgos. Ante la importancia del enfoque, que en este punto carece de actitud explicativa, consideramos interesante que sea en las noticias de crónica política y sociedad en las que se profundice para formar a la audiencia sobre desinformación y las consecuencias de la difusión de fake news.

4. La duración de las informaciones también nos aportan resultados que nos llevan a plantear el escaso espacio que se les dedica, entre 1-2 minutos en un $55 \%$. Las entrevistas son las únicas que se expanden en su abordaje, aunque de las entrevistas halladas solamente una habla en su totalidad de la infodemia.

Observamos que la duración es mucho menor que la recogida en el análisis cuantitativo, pues una vez elaborado el análisis de contenido, averiguamos que de los minutos catalogados solamente unos segundos se dedican a hablar de los bulos. Esto quiere decir que en su mayoría son noticias sobre política en las que se trata alguna desinformación de manera subyacente.

5. Tras estudiar la ubicación de la noticia en los informativos -Buenos días Andalucía, Noticias 1 , Noticias 2 y las desconexiones provinciales- recalcamos la falta de espacio en la apertura o titulares (5\%), esto refleja el insuficiente grado de importancia otorgado por Canal Sur Tv. a la agenda de las fake news. Las noticias falsas que se ubican al principio coinciden con la temática sanidad y política, mientras a la mitad se sitúan las entrevistas a expertos.

Las noticias que aparecen al final (30\%), previa a los deportes, son las dedicadas a la explicación del fenómeno comunicativo desde una perspectiva pedagógica. Aquí sí que encontramos algunas noticias que se refieren a plataformas o aplicaciones de fact-checking para combatir la desinformación o que son altavoz de instituciones como la OMS o el Gobierno alertando de la difusión de los bulos.

6. El número de totales y la elección de los actores nos reportan que el rol político interviene con el objetivo de denunciar el bulo o explicar hasta qué punto le repercute a su 
persona, mientras que los expertos sí aportan información para entender la procedencia e intencionalidad de las fake news. Aquí hay que precisar que los expertos en comunicación carecen prácticamente de presencia en las noticias, a pesar de ser los que más podrían aportar para entender el fenómeno comunicativo. Como apostilla Laguillo: «La lucha contra la posverdad, los bulos y las falsas noticias pasa, inexorablemente, por el buen periodismo» (Laguillo, 2020: 267).

7. Si atendemos a la composición de la información aseveramos que las entrevistas de expertos para abordar en profundidad nuestra temática se enmarcan dentro de los temas medios de comunicación y sanidad. En estos formatos especialistas en medicina, ciberseguridad y comunicación alertan de las desinformaciones y de sus repercusiones (causa-efecto). Coincidiendo también en ser las que más tiempo ocupan, más de 3 minutos, sugieren pautas y herramientas para instruir al telespectador y contribuir a la veracidad informativa a través de la alfabetización mediática.

8. El desenlace de las noticias se queda sin solución en un $48 \%$, lo que nos lleva a pensar en una necesidad sin cubrir por parte de los medios de comunicación. Apostamos por una labor ética desde la televisión en la que los profesionales de la información actúen como «agentes morales» con el objetivo de enfrentarse «a la disinformation, misinformation, fakenews y posverdad para alcanzar una Infosfera transparente y accesible» (Estrada-Cuzcano, Alfaro-Mendives y Saavedra-Vásquez, 2020: 102-103).

Aunque la lucha contra los desórdenes informativos necesita de la transparencia de instituciones y gobiernos, coincidimos con Torres Soriano al apostar por
el intercambio informativo entre los actores que luchan contra la desinformación, el apoyo a las iniciativas privadas que realizan labores de fact-checking, la medición del impacto de estas campañas, la disuasión del agresor mediante un coste mayor que el beneficio, el fortalecimiento del ecosistema de medios y el apoyo en la tecnología mediante algoritmos que neutralicen a los trolls individuales, foros de internet y pro- veedores de clickbait (Torres Soriano, 2020: 10-15).

No podemos centrar los esfuerzos en usar únicamente a los medios de comunicación como herramientas de fact-checking (García-Marín, 2020: 16), pues aunque la desinformación hay que desmentirla «la lucha contra la desinformación debe incluir estrategias multidimensionales adicionales y complementarias».

Coincidimos con el enfoque de Estrada-Cuzcano, Alfaro-Mendives y Saavedra-Vásquez y apostamos por la alfabetización mediática de la audiencia para entender y contener el proceso de viralización de fake news, pues «los consumidores de información requieren desarrollar habilidades necesarias para ser críticos y creadores de información responsables» (Estrada-Cuzcano, Alfaro-Mendives y Saavedra-Vásquez, 2020: 102-103).

Todo esto se convierte en indispensable para conseguir «unos principios que pugnen por el mantenimiento de la democracia y la estabilización de la opinión pública» (Torres Soriano, 2020: 10-15). Alexandre-Benavent, Castelló-Cogollos y Valderrama-Zurián (2020) animan a los profesionales de la información a contribuir con la construcción de códigos de ética global y educar a la sociedad en la búsqueda, contraste y verificación informativa para conseguir detener la infoxicación. 
Esta investigación abre una nueva vía de análisis a los expertos en comunicación con el propósito de profundizar en el papel que ocupan las instituciones, organismos y medios en la concienciación de la audiencia con respecto a la desinformación. Continuaremos en esta línea de estudio con la intención de analizar otros medios de titularidad pública como RTVE, así como la comunicación institucional durante la pandemia, para establecer el grado de implicación de las televisiones y organismos públicos en la instrucción sobre desinformación. Consideramos que solo a través de esta vía se podrá proponer un decálogo de buenas prácticas para el tratamiento informativo de las fake news desde el ejercicio periodístico al mismo tiempo que la audiencia pone en valor los peligros de la desinformación.

A la finalización de este trabajo el Consejo de Seguridad Nacional aprueba la Orden $\mathrm{PCM} / 1030 / 2020$, de 30 de octubre, por la que se publica el procedimiento de actuación contra la desinformación con el objetivo de «mejorar y aumentar la transparencia con respecto al origen de la desinformación y a la manera en la que se produce y difunde, además de evaluar su contenido».

\section{Bibliografía}

ALEIXANDRE-BENAVENT, Rafael, CASTELLÓ-COGOLLOS, Lourdes y VALDERRAMA-ZURIÁN, Juan-Carlos (2020). »Información y comunicación durante los primeros meses de Covid-19. Infodemia, desinformación y papel de los profesionales de la información». Profesional de la información, 29(4), e290408. DOI: 10.3145/epi.2020.jul.08

AMORÓS GARCÍA, Marc (2018). Fake news. La verdad de las noticias falsas. Barcelona: Plataforma Editorial.

ANDRÉU ABELA, Jaime (2002). Las técnicas de análisis de contenido: Una revisión actualizada. Fundación Centro de Estudios Andaluces.

ARDĖVOL-ABREU, Alberto (2015). «Framing o teoría del encuadre en comunicación. Orígenes, desarrollo y panorama actual en España». Revista Latina de Comunicación Social, 70, 423-450. DOI: 10.4185/RLCS-2015-1053

BALL-ROKEACH, S. J. (1985). "The origins of individual media system dependency: A sociological framework». Communication Research, 12(4), 485-510. DOI: 10.1177/009365085012004003

BALL-ROKEACH, S. J. y DEFLEUR, M. L. (1976). A dependency model of mass-media effects. Communication Research, 3(1), 3-21. DOI: 10.1177/009365027600300101

BAQUERIN DE RICCITELLI, María Teresa y SCARICABAROZZI, Rossana (2010). «La construcción mediática de la percepción social del riesgo». En VI Jornadas de Sociología de la UNLP. Universidad Nacional de La Plata. Facultad de Humanidades y Ciencias de la Educación. Departamento de Sociología, La Plata. Recuperado de https://www.aacademica.org/000-027/685.pdf

BARLOVENTO COMUNICACIÓN (2020). Cambio de hábitos y preferencias de la ciudadanía española frente al televisor por la crisis del coronavirus. Informe especial, marzo 2020. Recuperado de https://www.barloventocomunicacion.es/wp-content/uploads/2020/04/Informe-especial-coronavirus-MARZO-2020-ACTUALIZADO.pdf.

BARROSO Francisco Javier (2019). «Los procesos de gestión y obtención de la información desde los medios de comunicación social. Su utilidad práctica aplicada». En La función de inteligencia en la gestión de emergencias y catástrofes. Madrid: Ministerio de Defensa, Instituto Español de Estudios Estratégicos, págs. 167-188. Recuperado d: https://dialnet.unirioja.es/servlet/libro?codigo=732785 
CAA (2020). Informe sobre el tratamiento informativo de la crisis del coronavirus en Canal Sur TV. Junta de Andalucía. Consejo Audiovisual de Andalucía. Recuperado de https://www.consejoaudiovisualdeandalucia.es/sites/default/files/informe/pdf/2007/informe_covid-canal_sur.pdf

CALDEVILLA DOMÍNGUEZ, David y GARCÍA GARCÍA, Enrique (2020). «Profesionales y posverdad: La responsabilidad colectiva como arma contra la falacia digitalizada». aDResearch: Revista Internacional de Investigación en Comunicación, 21, 70-83. DOI:10.7263/adresic-021-04

CASERO-RIPOLLÉS, Andreu (2008). «La producción de la información audiovisual». En Marzal-Felici, Javier \& López Cantos, Francisco (eds.): Teoría y técnica de la producción audiovisual. Valencia: Tirant lo blanc.

CASERO-RIPOLLÉS, Andreu (2020). «Impact of Covid-19 on the media system. Communicative and democratic consequences of news consumption during the outbreak». Profesional de la información, 29(2), e290223. DOI: 10.3145/epi.2020.mar.23

CATALÁN-MATAMOROS, Daniel (2020). «La comunicación sobre la pandemia del Covid-19 en la era digital: manipulación informativa, fake news y redes sociales». Revista Española de Comunicación en Salud, Suplemento 1. DOI: 10.20318/recs.2020.5531

ESTRADA-CUZCANO, Alonso, ALFARO-MENDIVES, Karen y SAAVEDRA-VÁSQUEZ, Valeria (2020). «Disinformation y misinformation, posverdad y fake news: precisiones conceptuales, diferencias, similitudes y yuxtaposiciones». Información, Cultura Y Sociedad, (42), 93-106. DOI: 10.34096/ics. i 42.7427

FERNÁNDEZ, Itziar, MARTíN BERISTAIN, Carlos y PÁEZ, Darío (1999). «Emociones y conductas colectivas en catástrofes: ansiedad y rumor y conductas de pánico». En Apalategui, Jokin (Ed.). La anticipación de la sociedad. Psicología Social de los movimientos sociales. Valencia: Promolibro, págs. 281-342.

GARCÍA-MARÍN, David (2020). «Infodemia global. Desórdenes informativos, narrativas fake y fact-checking en la crisis de la Covid-19». Profesional de la información, 29(4), e290411. DOI: 10.3145/ epi.2020.jul.11

GHEBREYESUS, Tedros Adhanom (2020). «La desinformación frente a la medicina: hagamos frente a la "infodemia"». El País, 18 de febrero. Recuperado de https://www.who.int/es/news-room/commentaries/detail/coronavirus-infodemic

GÓMEZ DE AGREDA, Ángel (2018). «Posverdad y "fake new". Falsas noticias, no noticias falsas». Telos: Cuadernos de Comunicación e Innovación, 109, 18-21. Recuperado de https://telos.fundaciontelefonica.com/telos-109-asuntos-de-comunicacion-falsas-noticias-no-noticias-falsas/

HABERMAS, Jürgen. (1992). «Further reflections on the public sphere». En Calhoun. Craig (Ed.). Habermas and the Public Sphere. Massachusetts: MIT Press.

IGARTUA, Juan-José, ORTEGA-MOHEDANO, Félix y ARCILA-CALDERÓN, Carlos (2020). "Communication use in the times of the coronavirus. A cross-cultural study". Profesional de la información, 29(3), e290318. DOI: 10.3145/epi.2020.may.18

IRETON, Cherilyn y POSETTI, Julie (2018). Journalism, 'fake news' \& disinformation: handbook for journalism education and training. Paris: Unesco Publishing. Recuperado de https://digitallibrary. un.org/record/1641987? In=es

LAGUILLO, David (2020). «La esfera de Platón: "individuos sombra" y "ciudadanos" ante la pandemia de bulos sobre el coronavirus Covid-19». Revista Española de Comunicación en Salud, Suplemento 1. DOI: $10.20318 /$ recs.2020.5419 
LÁZARO-RODRÍGUEZ, Pedro y HERRERA-VIEDMA, Enrique (2020). Noticias sobre Covid-19 y 2019nCoV en medios de comunicación de España: el papel de los medios digitales en tiempos de confinamiento. Profesional de la información, 29(3), e290302. DOI: 10.3145/epi.2020.may.02

LIPPMANN, Walter (1922). Public Opinion. New York: Harcourt, Brace and Company.

LÓPEZ-RICO, Carmen María, GONZÁLEZ-ESTEBAN, José-Luis y HERNÁNDEZ-MARTíNEZ, Alberto (2020). «Polarización y confianza en los medios españoles durante el Covid-19. Identificación de perfiles de audiencia». Revista Española de Comunicación en Salud, Suplemento 1, pp. 77-89. DOI: $10.20318 /$ recs.2020.5439

MACEDO GARCÍA, Alejandro (2017). La agenda setting y el framing en situaciones de crisis. Estudio de caso la cobertura informativa en La Jornada y el Reforma sobre el desafuero del Jefe de Gobierno de la Ciudad de México. Tesis Doctoral. Universidad Complutense de Madrid. Recuperado de https://eprints.ucm.es/42248/1/T38686.pdf

MASIP, Pere, ARAN-RAMSPOTT, Sue, RUIZ-CABALLERO, Carlos, SUAU, Jaume, ALMENAR, Ester y PUERTAS-GRAELL, David (2020). Consumo informativo y cobertura mediática durante el confinamiento por el Covid-19: sobreinformación, sesgo ideológico y sensacionalismo. Profesional de la información, 29(3), e290312. DOI: 10.3145/epi.2020.may.12

MCCOMBS, Maxwell E. (2006). Estableciendo la agenda. El impacto de los medios en la opinión pública y en el conocimiento. Barcelona: Paidós

MCCOMBS, Maxwell E. y SHAW, Donald L. (1972). «The agenda setting function of mass media». Public Opinion Quarterly, 36, 176-187. DOI: 10.1086/267990

MOREJÓN LLAMAS, Noemí (2014). Los Indignados: ¿primera utopía del siglo XXI? Aproximación al contexto, génesis y desarrollo del movimiento 15-M en España a través de documentos bibliográficos, hemerográficos y digitales y comparación con la teoría utópica. Tesis Doctoral. Universidad de Sevilla, Sevilla.

MORENO, Ángeles, FUENTES-LARA, Cristina y NAVARRO, Cristina (2020). «Covid-19 communication management in Spain: Exploring the effect of information-seeking behavior and message reception in public's evaluation». El profesional de la información, 29(4), e290402. DOI: 10.3145/epi.2020.jul.02 NÚÑEZ-GÓMEZ, Patricia, ABUÍN-VENCES, Natalia, SIERRA-SÁNCHEZ, Javier y MAÑAS-VINIEGRA, Luis (2020). «El enfoque de la prensa española durante la crisis del Covid-19. Un análisis del framing a través de las portadas de los principales diarios de tirada nacional». Revista Latina de Comunicación Social, 78, 41-63. DOI: 10.4185/RLCS-2020-1468

ORDEN PCM/1030/2020, de 30 de octubre, por la que se publica el Procedimiento de actuación contra la desinformación aprobado por el Consejo de Seguridad Nacional. Recuperado de: https://www. boe.es/eli/es/o/2020/10/30/pcm1030

PÉREZ-DASILVA, Jesús-Ángel, MESO-AYERDI, Koldobika y MENDIGUREN-GALDOSPÍN, Terese (2020). «Fake news y coronavirus: detección de los principales actores y tendencias a través del análisis de las conversaciones en Twitter». Profesional de la información, 29(3), e290308. DOI: 10.3145/epi.2020.may.08

RAMÓN FERNÁNDEZ, Francisca (2020). “Comunicación y noticias falsas en relación al COVID-19: algunas reflexiones sobre la información, la desinformación y propuestas de mejora». Revista Española de Comunicación en Salud. Suplemento 1. DOI: 10.20318/recs.2020.5375

RAMONET, Ignacio (1998). La tiranía de la comunicación. Madrid: Temas de Debate.

REY, Jesús, LADERO, Víctor y MUÑOZ, Emilio (2020). "Covid-19 genera miedo e incertidumbre. El peligro de los escépticos y los sarcásticos ante la pandemia». Asociación Española para el Avance de la Ciencia (AEAC). Recuperado d: https://aeac.science/covid19-miedo-e-incertidumbre/ 
ROCHE CÁRCEL, Juan A. (2009). «Aceleración y tiranía del presente. La metamorfosis en las estructuras temporales de la modernidad de Josetxo Beriain». Política Y Sociedad, 46(1), 305-307. Recuperado de https://revistas.ucm.es/index.php/POSO/article/view/POSO0909130305A

RODRÍGUEZ PÉREZ, Carlos (2019). «No diga fake news, di desinformación: una revisión sobre el fenómeno de las noticias falsas y sus implicaciones». Comunicación, 40, 65-74. DOI: 10.18566/ comunica.n40.a05

ROGERS, Everett M. y DEARING, James W. (1988). «Agenda setting research: Where has it been? Where is it going?». Annals of the International Communication Association, 11, 555-594. DOI: 10.1080/23808985.1988.11678708

RTVA (2020). "Canal Sur aumenta la audiencia diaria y mantiene la misma cuota de pantalla que antes de la crisis». RTVA, 13 mayo. Recuperado de https://www.canalsur.es/rtva/canal--sur-aumenta-laaudiencia-diaria-y-mantiene-la-misma-cuota-de-pantalla-que-antes-de-la-crisis/1583072.html

RUBIO FERRERES, José María (2009). “Opinión pública y medios de comunicación. Teoría de la agenda setting. Gazeta de Antropología, 25(1), artículo 01. Recuperado de http://hdl.handle. net/10481/6843

SALAVERRÍA, Ramón, BUSLÓN, Nataly, LÓPEZ-PAN, Fernando, LEÓN, Bienvenido, LÓPEZ-GOÑI, Ignacio y ERVITI, María-Carmen (2020). «Desinformación en tiempos de pandemia: tipología de los bulos sobre la Covid-19». Profesional de la información, 29(3), e290315. DOI: 10.3145/epi.2020. may. 15

SERRANO, Pascual (2009). Desinformación. Cómo los medios ocultan el mundo. Madrid: Editorial Península.

SIERRA CABALLERO, Francisco y MORENO GÁLVEZ, Francisco Javier (2011). Fundamentos de Teoría del periodismo. Sevilla: Universidad de Sevilla. Recuperado de https://idus.us.es/bitstream/handle/11441/99266/32.pdf?sequence=1\&isAllowed=y

TESO ALONSO, GEmma (2011). «Metodología aplicada para el análisis de las noticias televisivas sobre cambio climático desde perspectivas cruzadas». En Primeiro Seminario Internacional RESCLIMA. Recuperado de https://www.ucm.es/data/cont/media/www/pag-16429/GemmaTeso-RESCLIMA.pdf

TORRES SORIANO, Manuel Ricardo (2020). Democracia vs. desinformación. Propuestas para la protección de las sociedades abiertas. Fundación Centro de Estudios Andaluces, 87. Recuperado de: https://centrodeestudiosandaluces.es/publicaciones/n-87-democracia-vs-desinformacion-propuestas-para-la-proteccion-de-las-sociedades-abiertas

ZAROCOSTAS, John (2020). «How to fight an infodemic». The Lancet, 395 (10225), 676. DOI: 10.1016/ S0140-6736(20)30461-X 